\title{
Veri madenciliği yöntemleri kullanarak yoğun bakım ünitesindeki hastaların sınıflandırması
}

\section{Patent classification in intensive care unit using data mining methods}

\author{
Emine COŞKUN ${ }^{(D)}$, Esra GÜNDOĞAN ${ }^{\text {iD }}$, Mehmet KAYA ${ }^{(i D}$, Reda ALHAJJ ${ }^{1}$ (D) \\ Bilgisayar Mühendisliği Bölümü, Fırat Üniversitesi, Elazı̆̆g, Türkiye \\ ${ }^{1}$ Bilgisayar Mühendisliği Bölümü, İstanbul Medipol Üniversitesi, İstanbul, Türkiye \\ (coskemine@gmail.com, egundogan@firat.edu.tr, kaya @ firat.edu.tr, ralhajj@medipol.edu.tr)
}

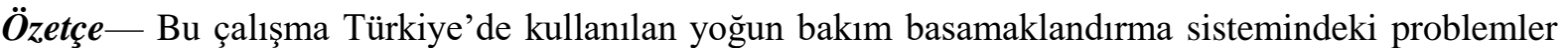
göz önüne alınarak hazırlanmıștır. Yoğun bakımlarda hasta bakımı, hastaların takibi, hastalıkların kontrolü ve tüm bunların maliyeti, içinde zorluklar barındıran işlemlerdir. Bu sistemin kontrolünü kolaylaştırmak bu çalışmanın en önemli amaçlarındandır. Çalışma veri madenciliği yöntemlerinin uygulanmasını içermektedir. Yoğun bakımlarda tedavi gören hastaların gerçek verileri ile çalışılmıştır. $\mathrm{Bu}$ veriler üzerinde basamak değerleri referans alınarak sınıflandırma ve kümeleme işlemi yapılmıştır. Çalışma aynı zamanda yoğun bakım basamak sayısının arttırılması yönünde bir öneriyi içermektedir. Anahtar Kelimeler: veri madenciliği, makine ögrenmesi, yoğun bakım.

\begin{abstract}
This study has been prepared by considering the problems in the intensive care classification system used in Turkey. In intensive care unit, patient care, patient follow-up, disease control and the cost of all these are procedures that have difficulties. Facilitating the control of this system is one of the most important aims of this study. The study includes the application of data mining methods. It has been studied with real data of patients treated in intensive care units. Classification and clustering processes have been performed on these data by taking place class values as reference. The study also includes a suggestion to increase the number of intensive care classes.
\end{abstract}

Keywords: data mining, machine learning, intensive care.

\section{Giriş}

Veri madenciliği yöntemlerinin sağlık uygulamalarında kullanımı her geçen gün yaygınlaşmaktadır. Hastane sistemlerinin bir parçası olan laboratuvar bilgi yönetim sistemleri veri tabanlarında depolanan hasta verileri; hastalık, hastalığın seyri ve hastalığın tedavisi konusunda sağlık profesyonellerine yol gösterecek, değerli bilgiler içermektedir. Depolanan bu verilerin, veri madenciliği yöntemleri yardımıyla yorumlanması, daha hızlı ve etkin kararlar alınmasına, buna bağlı olarak da sağlık hizmetlerinde kalitenin yükselmesine yardımcı olabilecektir [1]. Veri madenciliği çalışmalarının en doğru şekilde sürdürülebilmesi için büyük veri kaynakları gerekmektedir ve laboratuvar bilgi yönetim sistemleri bu çalışmalar için oldukça uygun veri setleri sunmaktadır [2].

Yoğun bakımlar, hastaların takibi, tedavisi, tedavi süresinin uzunluğu, kullanılan ekipmanların spesifikliği göz önüne alındığında sağlık sistemi içerisinde maliyeti en yüksek birimlerdir. Ülkemizde yoğun bakımlar hastalığın seviyesine göre basamaklara ayrılmaktadır. Birinci basamak, ikinci basamak ve üçüncü basamak olarak, üç seviye yoğun bakım bulunmaktadır. 
Birinci basamak: Yaşamsal risk doğurabilecek tıbbi durumların yakın takip edildiği, invaziv olmayan monitörizasyon yöntemlerine sahip, temel destek tedavilerin ve ilk stabilizasyonun sağlanabildiği, gerektiğinde ilgili kliniklerin içinde de yapılandırılabilen, 2. veya 3. seviye yoğun bakım servislerine hasta transferi yapabilen birimlerdir.

İkinci basamak: Temel monitörizasyon ve temel destek tedavilerin yanında, invaziv monitorizasyon ve tedavilerin de yapılabildiği, 3. Seviye yoğun bakım servislerine hasta transferi yapabilen yoğun bakım servisleridir.

Üçüncü basamak: Çoklu organ işlev bozukluğu gibi tüm komplike hastaların kabul edildiği, solunum desteği, renal replasman tedavisi, plazmaferez gibi destek tedavilerin sağlanabildiği, en üst düzeyde tıbbi bakım ve tedavi hizmeti verilen yoğun bakım servisleridir.

Yukarıda tanımları yapılan basamaklara göre fiyatlandırma yapılmaktadır. Çalışmanın yapıldığı tarih itibariyle sağlık uygulama tebliğindeki ücretlendirmeler şu şekildedir; birinci basamak yoğun bakım yatağı $253 \mathrm{TL}$, ikinci basamak yoğun bakım yatağı 537,63 TL, üçüncü basamak yoğun bakım yatağı 1012,7 TL.

Bu çalışmada Fırat Üniversitesi Hastanesinde 2010-2020 yılları arasında tedavi gören 2. ve 3. basamak yoğun bakım hastaları ele alınmıştır. Sınıflandırma algoritmaları kullanılarak hastaların bulunduğu basamak önceden tahmin edilmeye çalışılmıştır. Bunun dışında veri setine k-means kümeleme algoritması uygulanarak hastaların bölünmesi gereken optimum küme sayısı elde edilmiştir. Bu küme sayısı aynı zamanda bizim yeni basamak sayısı önerimizdir.

\section{2. İlgili Çalışmalar}

1985 y1lında Knaus ve arkadaşları tarafindan acute physiology and chronic health evaluation II (APACHE II) yayınlanmıştır. Bu skor yoğun bakım hastalarında, hastalığın seviyesini belirlemek ve ölüm tahmini için kullanılıyordu. Hastanın test sonuçlarını içeren 12 değişken 0 ile 4 arasında puanlanır. Hastanın yaşı da hesaba katılarak toplam APACHE II skoru elde edilmiş olur [3,4].

Le Gall ve arkadaşları tarafından A Simplified Acute Physiology Score for ICU Patients (SAPS) yayınlanmıştır. APACHE skorlama sistemine alternatif olarak geliştirilmiştir. Yoğun bakıma yatan hastanın ilk 24 saatinde ölçülen 14 değişkenin 0 ile 4 arasında puanlanması ile elde edilir. Tıpkı APACHE gibi hastalığın seyri hakkında tahminde bulunmak için kullanılır [5].

1995 yılında Marshall JC ve arkadaşları tarafindan Multiple Organ Dysfunction Score (MODS) yayınlanmıştır. Hastanın çalışmaz durumdaki organ sistemleri ile yoğun bakımdaki mortalite arasındaki ilişkiye dayanılarak oluşturulmuştur. Altı organ sisteminin değerlendirilmesi ve puanlanması sonucu olde edilir. Bir organ yetmezliği skorlama sistemi olan MODS morbiditeyi ölçmek için oluşturulmuştur [6].

Organ yetmezliği skorlama sistemleri içerisinde en fazla kullanılır durumda olan Sequential Organ Failure Assessment Score (SOFA) 1996 yılında Avrupa Yoğun Bakım Derneği tarafindan geliştirilmiştir. Bu sistemin amacı organ yetmezliğinin derecesini belirlemektir. Altı organ sistemine ait fizyolojik değişkenlerin puanlanması ile hesaplanır [7].

J. Ramon ve arkadaşları 2007 yılında yoğun bakım hastaları için bir veri madenciliği çalışması yayınlamıştır. Bu çalışmada 1548 adet yoğun bakım hastası ele alınmaktadır. Bu hastalar için hayatta kalma, 3 günden fazla yoğun bakımda kalma gibi 14 olasılığa yanıt aranmaktadır. Bu olasılıklara yanıt bulmak için dört veri madenciliği algoritması kullanılmıştır. Bunlar; Karar Ağaçları, Birinci Dereceden Rastgele Orman, Naïve Bayes, Tree Augmented Naïve Bayes algoritmalarıdır. Çalışma incelendiğinde DT dışındaki tüm algoritmalar doktor ve hemşire gözlemleri ile oldukça uyumludur. Bu sonuçlar ele alındığında algoritmaların gerçeğe yakın çalıştığ söylenebilir. Çünkü algoritmaların çalıştırıldığı veri setleri doktor ve hemşirelerin bildiğinden çok daha az bilgi içermektedir [8]. 


\section{Yoğun Bakımlarda Sınıflandırma ve Kümeleme}

Yoğun bakımlar kabul edebileceği hastaların klinik durumuna, sağlık personeli, donanım ve mekânsal özelliklerine göre basamaklandırılır. Yoğun bakım hastalarının klinik bulguları anlık olarak değişebilir ve bu hastalar yaşamsal faaliyetlerini çoğunlukla ilaç ve cihaz desteği ile sürdürebilir. Bu nedenle hastaların durumlarının öngörülebilmesi son derece önemlidir. Bunun dışında yoğun bakımlarda kaynaklar kısıtlıdır ve maliyetleri sağlık sistemi içerisinde en yüksek birimlerdir. Yani bu birimlerde kaynakların doğru kullanımı çok önemlidir [9].

\subsection{Veri Seti}

Kullanılan veri setinin ön işlemden geçmemiş hali içerisinde 52.673 adet hasta bulunduruyordu, 82 test ve 83. basamak (2. basamak ve ya 3.basamak) değeri olarak toplam 83 parametreye sahipti. Bu veri seti içerisinde bir ön işleme gerçekleştirildi. Az sayıda test verisi bulunan, kısa yatışlı hastalar veri setine dahil edilmedi. Parametrelerin seçimi için APACHE, SAPS, MODS ve SOFA skorlama sistemlerinden faydalanıldı. Ayrıca Craven ve ark.'nın [10] yaptıkları çalışmada yaş, yatış tanısı, enfeksiyon, lökopeni, hipoalbüminemi ve yoğun bakımda kalış süresinin uzunluğu risk faktörleri olarak saptanmıştır. $\mathrm{Bu}$ doğrultuda hastanın yoğun bakımda kalış süresi de göz önünde bulunduruldu. $\mathrm{Bu}$ parametre şöyle değerlendirildi; Hastanın yatış süresi 2 haftadan uzunsa 3 puan, 2 hafta ile 1 hafta arasında ise 2 puan, 1 haftadan az ise 1 puan olarak ele alındı. Akkoç ve ark.'nın [11] yaptığı çalışmada ölen hastaların genellikle taburcu olan hastalara göre laboratuvar parametrelerinden kreatinin, ürik asit, LDH düzeyleri, beyaz küre sayısı(wbc) ortalaması istatistiksel olarak anlamlı yüksek, albümin düzeyi ortalaması ise düşük bulunmuştur [12]. Literatürdeki bu çalışmalar 1şı̆̆ı̆nda parametreler seçildi. Daha sonra veri seti etkileşimi az testlerden arındırıldı ve 58 parametre ele alındı. Bu test verileri ise hastanın yoğun bakım ünitesi (YBÜ)'ne girdiği andaki sonuçları ve YBÜ'den çıkıştan hemen önceki sonuçları olarak iki ayrı grupta incelendi. Tüm bu işlemler sonucunda 31.834 adet hasta, 58 parametre ve 59 . basamak (2. basamak, 3. basamak) değeri olmak üzere toplam 59 parametreli bir veri seti elde edildi. Bazı hastalarda, bazı parametrelere karşılık gelen değerler yoktu ve bu değerler ortalama değer ile dolduruldu. Toplamda 1.846.372 adet test değeri ele alınmış oldu. Veri seti ile ilgili genel bir gösterim Figure 1'de yapılmıştır.

\begin{tabular}{|c|c|c|c|c|c|c|c|c|c|c|c|c|c|c|c|c|c|c|c|}
\hline & $\begin{array}{c}\text { Satir } \\
\text { Etiketleri }\end{array}$ & ALBUMIN & ALP & ALT & APTT & AST & BA\# & BA\% & CK & СK/MB & $\ldots$ & tBil & tHb & to2 & TRIGLISERIT & TROPONIN & URE & $\begin{array}{l}\text { URIK } \\
\text { ASIT }\end{array}$ & $\begin{array}{c}\text { VLDL } \\
\text { KOLESTEROL }\end{array}$ \\
\hline 0 & 3001237 & 4.0 & 77.0 & 13 & 32.421 & 22.0 & 0.01 & 0.10 & 42.0 & 21.00 & $\ldots$ & 15.0 & 4.30 & 5.6 & 84 & 0.02 & 68.0 & 3.9 & 17.0 \\
\hline 1 & 5198877 & 3.7 & 127.8 & 43 & 15.932 & 27.0 & 0.02 & 0.10 & 456.0 & 16.25 & & 0.0 & 18.90 & 22.3 & 163 & 0.00 & 33.0 & 0.6 & 32.7 \\
\hline 2 & 4064588 & 2.9 & 384.0 & 9 & 57.283 & 31.0 & 0.01 & 1.30 & 57.0 & 37.00 & $\ldots=$ & 52.0 & 17.40 & 18.2 & 163 & 2.66 & 15.0 & 1.7 & 32.7 \\
\hline 3 & 4695190 & 3.8 & 53.0 & 25 & 26.969 & 21.0 & 0.01 & 0.00 & 61.0 & 16.03 & $\ldots$ & 17.0 & 7.60 & 10.4 & 163 & 0.02 & 50.0 & 2.0 & 32.7 \\
\hline 4 & 5676499 & 2.0 & 115.0 & 63 & 31.832 & 69.0 & 0.01 & 0.00 & 104.0 & 116.59 & $\ldots$ & 1.0 & 23.00 & 30.5 & 163 & 0.32 & 76.0 & 2.0 & 32.7 \\
\hline$\ldots$ & & $\ldots$ & & $\cdots$ & & & & $\ldots$ & & & & & ... & & $\ldots$ & ... & ... & $\ldots$ & \\
\hline 31830 & 7053433 & 3.6 & 111.0 & 44 & 30.000 & 61.9 & 0.03 & 0.37 & 350.0 & 58.10 & ... & 8.4 & 12.12 & 12.9 & 144 & 6.00 & 54.8 & 5.9 & 28.8 \\
\hline 31831 & 7691015 & 3.6 & 111.0 & 44 & 30.000 & 61.9 & 0.03 & 0.37 & 350.0 & 58.10 & $\ldots$ & 8.4 & 12.12 & 12.9 & 144 & 6.00 & 54.8 & 5.9 & 28.8 \\
\hline 31832 & 8440107 & 3.6 & 111.0 & 44 & 30.000 & 61.9 & 0.03 & 0.37 & 350.0 & 58.10 & $\ldots$ & 8.4 & 12.12 & 12.9 & 144 & 6.00 & 54.8 & 5.9 & 28.8 \\
\hline 31833 & 8648625 & 3.6 & 111.0 & 44 & 30.000 & 61.9 & 0.03 & 0.37 & 350.0 & 58.10 & & 8.4 & 12.12 & 12.9 & 144 & 6.00 & 54.8 & 5.9 & 28.8 \\
\hline 31834 & 8707670 & 3.6 & 111.0 & 44 & 30.000 & 61.9 & 0.03 & 0.37 & 350.0 & 58.10 & $\ldots$ & 8.4 & 12.12 & 12.9 & 144 & 6.00 & 54.8 & 5.9 & 28.8 \\
\hline
\end{tabular}

Şekil 1. Veri setinin gösterimi

\subsection{Kullanılan Algoritmalar}

\subsubsection{Destek Vektör Makineleri}

Destek vektör makinesi algoritmaları benzer özelliklere sahip verilerin sınıflara ayırılması için kullanılır. Bir düzlem üzerinde bulunan noktaları ayırmak için bir doğru çizer. Bu doğrunun, iki sınıfın noktaları için de maksimum uzaklıkta olması gerekir. Karmaşık ama küçük ve orta ölçekteki veri setleri için uygulanabilir [13]. 


\subsubsection{K En Yakın Komşu}

KNN algoritması sınıflandırılmak istenen bir veriyi daha önceki verilerle olan yakınlı ilişkisine göre sınıflandıran bir algoritmadır. İlk olarak bir k değeri belirlenmelidir. Sınıflandırılmak istenen yeni veri en yakın k adet komşusunun dahil olduğu sınıflar gözlemlenerek bir sınıfa dahil edilir. Yeni verinin dahil edileceği sınıfı belirlemek için uzaklık fonksiyonları kullanılır. Bunlardan en çok kullanılan denklem 1'de gösterilen öklid uzaklığıdır [14].

$$
\left(\sqrt{\sum_{i=1}^{n}\left(x_{i}-y_{i}\right)^{2}}\right)
$$

\subsubsection{Karar Ağaçları}

Karar ağaçları, karar düğümleri ve yaprak düğg̈mlerinden oluşan bir sınıflandırma yöntemidir. Bu algoritmalarda veri seti küçük parçalara bölünür ve bir karar dügümü ile birden fazla dallanma içerebilir. İlk düğüm kök dügümdür ve bilgi kazancı en yüksek olan özellik kök düğüm olarak seçilir.

\subsubsection{Rastgele Orman Algoritması}

Denetimli bir öğrenme algoritması olan rastgele orman birden fazla karar ağacını birleştirerek sınıflandırma yapmaktadır. Bir düğümün en önemli özelleiğini arayarak dügümü parçalara ayırmak yerine rastgele bir özellik alt kümesinden en iyi özelliği arar. Düğüm olarak adlandırılan sınıflar, üyeleri

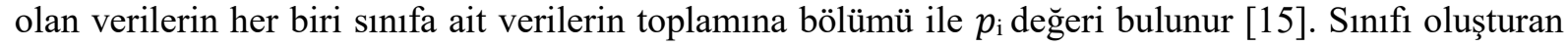
verilerin her birinin $p_{i}$ değeri bulunur ve sınıfların bilgi kazancı değeri denklem 2'deki formül ile ölçülür.

$$
B(T)=1-\sum_{i=1}^{n} p_{i}^{2}
$$

\subsubsection{K-means Algoritması}

K-means algoritması denetimsiz bir öğrenme algoritmasıdır. Ayrıca kümeleme algoritmaları içinde en fazla kullanılanıdır. Denetimsiz öğrenme, modelin bilgi keşfetmek için dışarıdan müdahaleye ihtiyaç duymaması anlamına gelir. Denetimli algoritmaların aksine etiketlenmemiş verilerle ilgilenir. $\mathrm{Bu}$ yöntem veri seti içerisinde göremediğimiz kalıpları bulmamızı sağlar. Algoritmanın genel çalışma prensibi $\mathrm{n}$ adet veri nesnesinden oluşan bir veri setini, başlangıçta parametre olarak verilen $\mathrm{k}$ adet kümeye ayırmaktır. Oluşan $\mathrm{k}$ adet kümede küme içi benzerliklerin çok fazla, kümeler arası benzerliklerin ise az olması beklenmektedir. Yine uzaklık fonksiyonu olarak Öklid uzaklık formülü kullanılır. Öklid uzaklık formülü denklem 3'te gösterilmektedir.

$$
\left(\sqrt{\sum_{\mathrm{i}=1}^{\mathrm{n}}\left(\mathbf{x}_{\mathbf{i}}-\mathbf{y}_{\mathbf{i}}\right)^{2}}\right)
$$

K-means algoritmasının işlem basamakları;

- $\quad \mathrm{k}$ değerinin belirlenmesi, $\mathrm{k}$ adet nesne küme merkezleridir. M1, M2,...,Mk

Orta noktanın hesaplanması denklem 4'te gösterilmiştir:

$$
M_{k}=\frac{1}{n_{k}} \sum_{i=1}^{n_{k}} x_{i k}
$$

- Küme içi değişimler ve karesel hata denklem 5'te gösterilmiştir:

$$
\boldsymbol{e}_{i}^{2}=\sum_{i=1}^{n_{k}}\left(x_{i k}-M_{k}\right)^{2}
$$

Hata hesaplama formülü denklem 6'da gösterilmiştir:

$$
\sum_{k}^{2}=\sum_{k=1}^{k} e_{k}^{2}
$$


- Her veri kendisine en yakın kümeye dahil edilir.

- Tüm veriler dahil edildikten sonra yeni küme merkezleri hesaplanır.

- Küme merkezlerinde değişiklik olmayana kadar 2. ve 3. adımlar tekrarlanır [16,17].

Elbow Metodu: K-means algoritmasının verimliliği için en önemli etmen k değerinin seçimidir. Doğru k değerini seçmek için çeşitli yöntemler vardır. Bunlardan en çok öne çıkan Elbow metodu yani dirsek yöntemidir. Within Cluster Sum of Square kısaca WCSS değeri hesaplanır. Bu değer her bir verinin küme merkezine olan uzaklığının kareleri toplamı alınarak hesaplanır. WCSS'deki değişim miktarının azaldığı nokta dirsek noktası olarak adlandırılır ve en doğru k değeri olduğu söylenir [18]. Şekil 2'de örnek bir dirsek yöntemi grafiği gösterilmektedir. Grafikte 1, 2, 3 ve 4 değerlerinde WCSS'nin değişimi çok büyükken 5 değerinden itibaren durağanlaşmaktadır. Buna göre en doğru k değeri 5 'tir diyebiliriz $[12,17]$.

\subsection{Performans Ölçütleri}

\subsubsection{Konfüzyon Matrisi}

Konfüzyon matrisi algoritmaların doğruluğunu ölçmekte kullanılan bir performans değerlendirme aracıdır. Şekil 2'de konfüzyon matrisi ile ilgili bir gösterim yapılmıştır.

\begin{tabular}{|c|c|c|c|}
\hline & \multicolumn{2}{|c|}{ Var olan Durum } \\
\hline & & $\begin{array}{c}\text { Pozitif } \\
\text { Durumlar }\end{array}$ & $\begin{array}{c}\text { Negatif } \\
\text { Durumlar }\end{array}$ \\
\hline \multirow{2}{*}{ 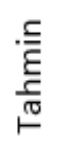 } & Pozitif & TP & $\mathrm{FP}$ \\
\hline & Negatif & FN & TN \\
\hline
\end{tabular}

Şekil 2. Konfüzyon matrisi

TP: True Positive, TN: True Negative, FP: False Positive, FN: False Negative

\subsubsection{Doğruluk}

Bir algoritmanın başarısını ölçmek için sıklıkla başvurulan bir yöntemdir. Konfüzyon matrisinde true positive ve true negative olan değerlerin tüm değerlere bölümü ile elde edilir. Başarı ölçümü için tek başına yeterli olduğu söylenemez [20]. Denklem 7'de doğruluk hesaplaması için kullanılan formül verilmiştir.

$$
\text { Doğruluk }=\frac{\mathrm{TP}+\mathrm{TN}}{\mathrm{TP}+\mathrm{TN}+\mathrm{FP}+\mathrm{FN}}
$$

\subsubsection{Duyarlılık}

Pozitif olması gereken değerlerin ne kadarının algoritma tarafından pozitif olarak değerlendirildiğini ölçen bir yöntemdir. True positive değerlerin, true positive ve false negative değerlerin toplamına bölümü ile elde edilir [19]. Denklem 8'de duyarlılık hesaplaması için kullanılan formül verilmiştir.

$$
\text { Duyarlılık }=\frac{\mathrm{TP}}{\mathrm{TP}+\mathrm{FN}}
$$

\subsubsection{Kesinlik}

Algoritmanın pozitif olarak tahmin ettiği değerlerin ne kadarının gerçekten pozitif olduğunu ölçmeyi sağlayan yöntemdir. True positive değerlerin, true positive ve false positive değerlerin toplamına bölümü ile elde edilir [20]. Denklem 9'da kesinlik hesaplaması için kullanılan formül verilmiştir. 


$$
\text { Kesinlik }=\frac{\mathrm{TP}}{\mathrm{TP}+\mathrm{FP}}
$$

\subsubsection{F1 Skor}

$\mathrm{Bu}$ yöntem kesinlik ve duyarlılı̆̆ın harmonik ortalamışıdır. 0 ile 1 arasında değer alabilir. Algoritmanın doğruluğunu ölçmek için kullanılır. Denklem 10'da F1 skor hesaplaması için kullanılan formül verilmiştir.

$$
\text { F1 Skor }=\frac{2 * \text { Duyarlılık } * \text { Kesinlik }}{\text { Duyarlılık }+ \text { Kesinlik }}
$$

\section{Deneysel Çalışmalar}

Fırat Üniversitesi Hastanesi Yoğun Bakım Ünitesinde 2010 ile 2020 yılları arasında tedavi gören 2. ve 3. basamak yoğun bakım hastaları ele alınmıştır. Algoritmaların çalıştırılabileceği bir hale gelen veri seti, \%80 eğitim veri seti, \%20 test veri seti olarak ayrılmıştır. Sınıflandırma algoritmalarından K-NN, Destek Vektör Makineleri, Karar Ağaçları ve Rastgele Orman algoritmaları veri setine uygulanmıştır. Algoritmaların eğitimlerinin tamamlanmasının ardından test veri seti ile performans ölçümü gerçekleştirilmiştir. Ayrıca sınıflandırma algoritmaları hastanın YBÜ'ye girişi ve çıkışında ölçülen sonuçlar olarak iki ayrı şekilde test edilmiştir. Hastanın hastaneye andaki sonuçları için konfüzyon matrisi Şekil 3'te, taburcu olmadan hemen önceki sonuçları Şekil 4'te gösterilmiştir.
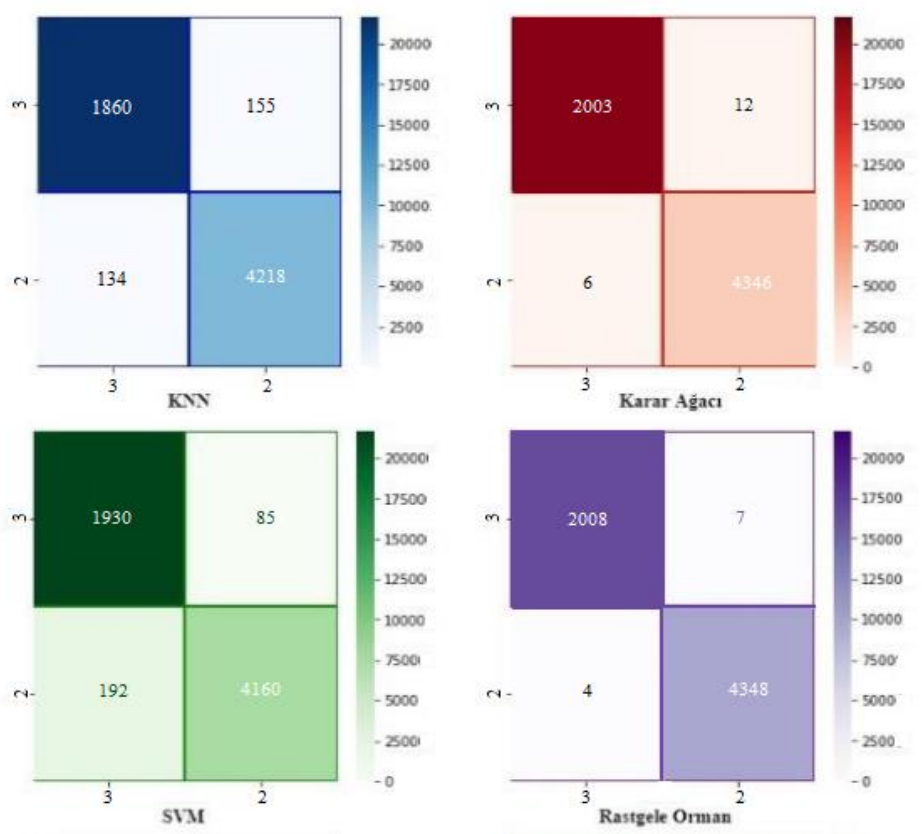

Şekil 3. Hastanın hastaneye giriş anındaki sonuçları için konfüzyon matrisi

K-NN algoritmasında $\mathrm{k}$ değerinin seçimi önemlidir. Optimum $\mathrm{k}$ değerinin seçimi ile ilgili grafik Şekil 5 'te gösterilmiştir. En yüksek doğruluk değeri $\mathrm{k}=4$ iken elde edildiği için $\mathrm{k}$ değeri 4 olarak seçilmiştir. 

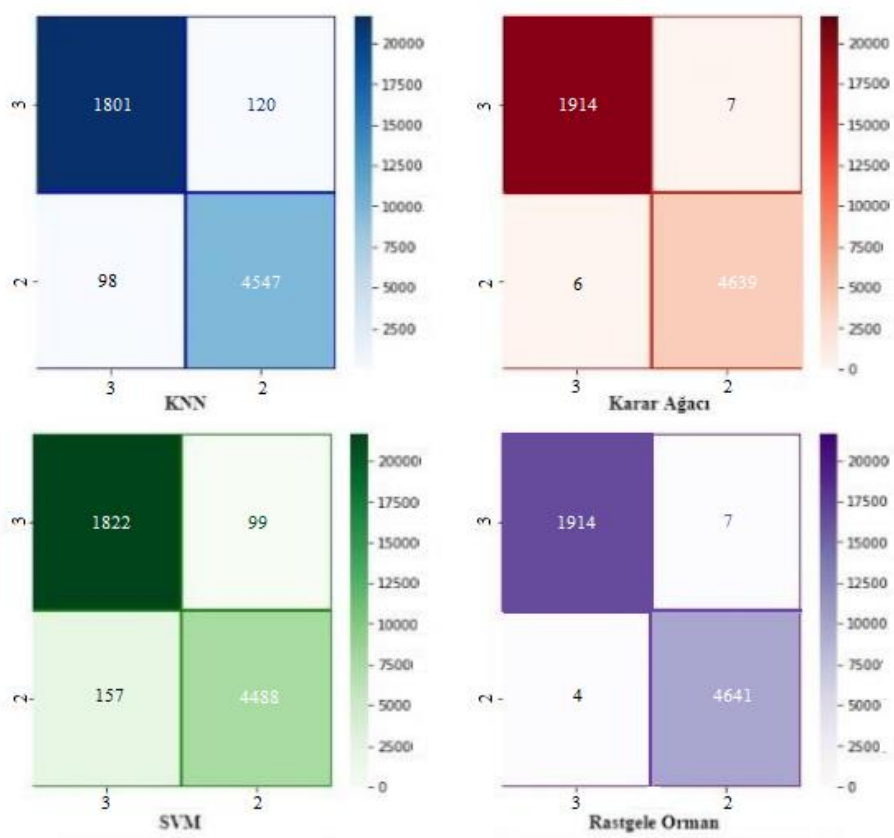

Şekil 4. Hastanın taburcu olmadan hemen önceki sonuçları için konfüzyon matrisi

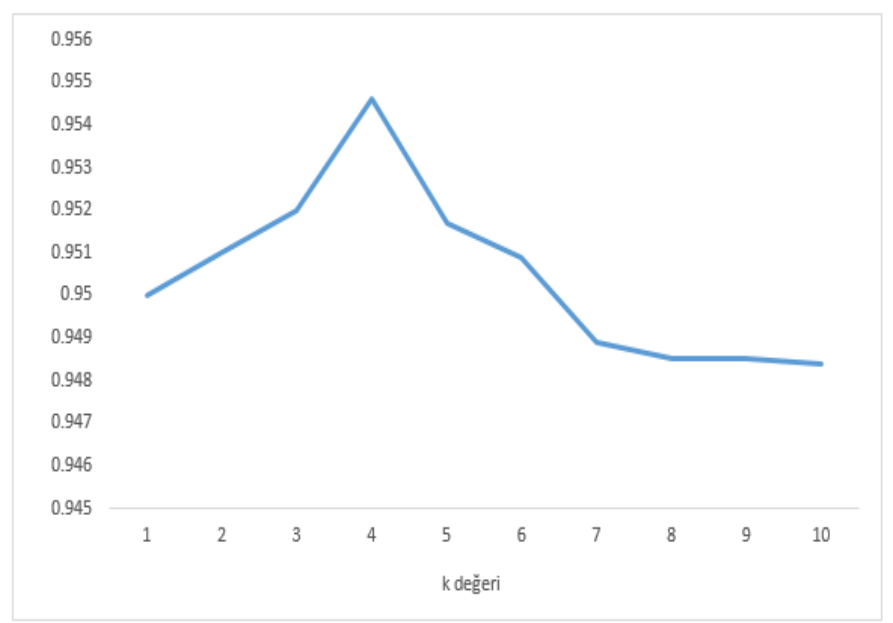

Şekil 5. Optimum k seçimi

Tablo 1'de hastanın giriş anında alınan test değerlerine göre test edilen algoritmaların, Tablo 2'de hastanın taburcu edilmeden hemen önceki test değerlerine göre test edilen algoritmaların performans ölçütü değerlerine yer verilmiştir. Tüm algoritmalarda hastanın taburcu edilmeden hemen önceki değerlerinin daha doğru sonuçlar verdiği görülmüştür. Doğruluk değerinin en yüksek olduğu algoritmanın 0,998 ile rastgele orman, en düşük olduğu algoritmanın ise 0,954 ile K-NN olduğu görülmektedir.

Tablo 1. Hastanın giriş verileri için performans ölçütleri

\begin{tabular}{|l|l|l|l|l|}
\hline Algoritmalar & Doğruluk & Duyarlılık & Kesinlik & F1-skor \\
\hline K - NN & 0,954 & 0,955 & 0,955 & 0,955 \\
\hline SVM & 0,956 & 0,956 & 0,958 & 0,957 \\
\hline Karar Ağac1 & 0,997 & 0,997 & 0,997 & 0,997 \\
\hline Rastgele Orman & 0,998 & 0,998 & 0,998 & 0,998 \\
\hline
\end{tabular}


Kesinlik ve duyarlılık ölçütlerini tek başına ele alarak algoritmaların performansı hakkında bilgi sahibi olunabilir ama kesin sonuç olduğu söylenemez. Bu konuda kesin bir yargıya varmak için duyarlılık ve kesinlik değerlerinden faydalanılarak hesaplanan F1-skor ölçütüne bakmamız gerekir. Tablo 1 ve Tablo 2'de F1-Skorları görülebilir.

Tablo 2. Hastanın çıkış verileri için performans ölçütleri

\begin{tabular}{|l|l|l|l|l|}
\hline Algoritmalar & Doğruluk & Duyarlılık & Kesinlik & F1-skor \\
\hline K - NN & 0,966 & 0,967 & 0,967 & 0,967 \\
\hline SVM & 0,961 & 0,961 & 0,962 & 0,961 \\
\hline Karar Ağacı & 0,998 & 0,998 & 0,998 & 0,998 \\
\hline Rastgele Orman & 0,998 & 0,998 & 0,998 & 0,998 \\
\hline
\end{tabular}

K-means algoritması hastaların çıkışındaki değerlerin olduğu veri setine uygulanmıştır. $\mathrm{Bu}$ algoritma ile sınıf etiketi devre dışı bırakılarak değerlerin birbirine yakınlığına göre kümeler oluşması sağlanır. Amaç daha sonra gelen verinin hangi kümeye dahil olacağının otomatik olarak belirlenmesidir. Optimum k değerinin bulunması için daha farklı bir ifade ile bu veri seti kaç kümeye bölündüğünde en doğru bölümleme yapılmış olacağını belirlemek için Elbow Metodu yani dirsek yöntemi kullanılmıştır.

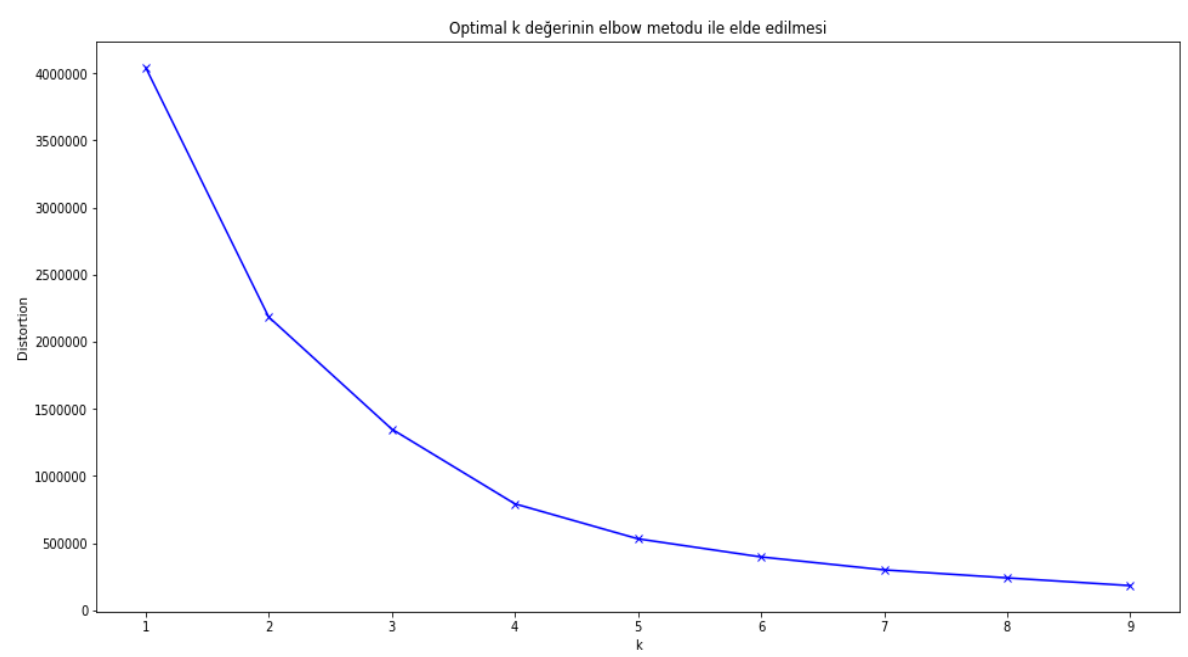

Şekil 6. Elbow metodu ile K-means için optimal k değeri grafiği

Grafik yorumlanırken metodun adını aldığı dirsek şeklinden faydalanılır. Grafiğin düzleşmeye başladığ 1 nokta yani dirsek noktası optimum k olarak kabul edilir. Şekil 6'da göre optimum k, "4" olarak seçilmelidir. Buradan çok önemli bir sonuç çıkarılabilir. Üç basamaklı yoğun bakım sisteminin yetersiz gelmesi sorunu, basamak sayısı 4'e çıkarıldığında olumlu yönde değişiklik gösterebilecektir. Şekil 7'de k-means algoritmasının k, 2 seçildiğinde çıkan sonucu, Şekil 8'de ise $\mathrm{k}, 4$ seçildiğinde çıkan sonucu gösterilmektedir. $\mathrm{Bu}$ şekillerden de veri setinin 4 kümeye bölünmesinin daha doğru olacağı görülmektedir.

\section{Sonuç}

Gerçek hastalık verileri kullanılarak veri madenciliğinde sınıflandırma algoritmaları eğitildi ve test edildi. Test verilerinin doğruluk, kesinlik, duyarlılık ve F1 skoru metrikleri ile performansları ölçüldü ve başarılı sonuçlar elde edildi (Tablo 1, Tablo 2). Ayrıca bu sonuçlara göre hastanın bulunduğu basamağı saptamak için hastanın YBÜ'YE alındığı andaki değerleri değil, YBÜ'den çıkmadan hemen önceki değerleri baz alınmalıdır. Tablo 2 ve Tablo 2'de gösterildiği üzere bu çalışmada en doğru sonuç karar ağaçları ve rastgele orman algoritmalarından elde edildi. K-means algoritması ile kümeleme işlemi yapıldı. Burada elde edilen en önemli sonuç 3 basamaklı yoğun bakım sisteminin bir basamak daha eklenerek 4 basamaklı sisteme dönüştürülmesi ile daha verimli hizmet sunulabilecek olmasidır. 


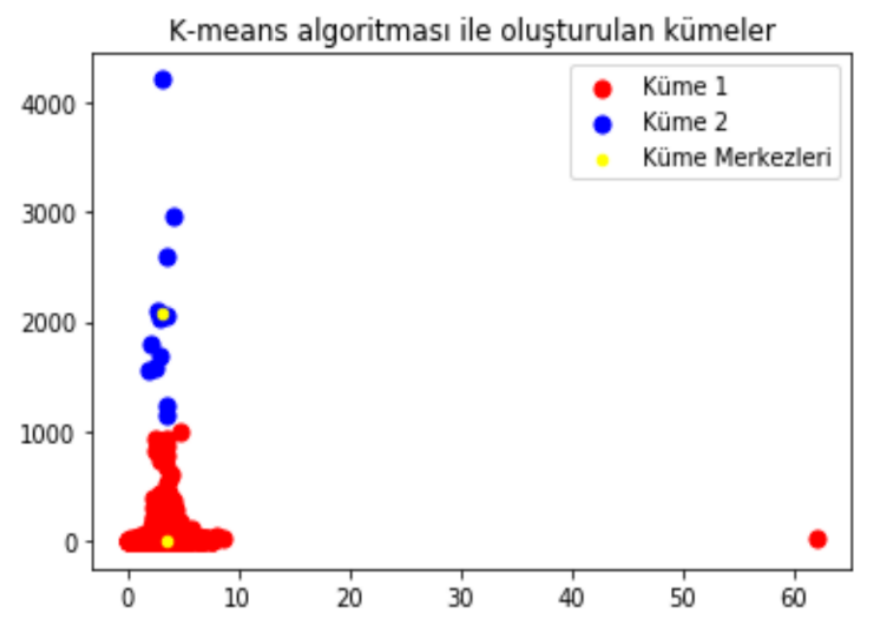

Şekil 7. Veri setinin k=2 iken k-means algoritması ile kümelenmiş grafiği

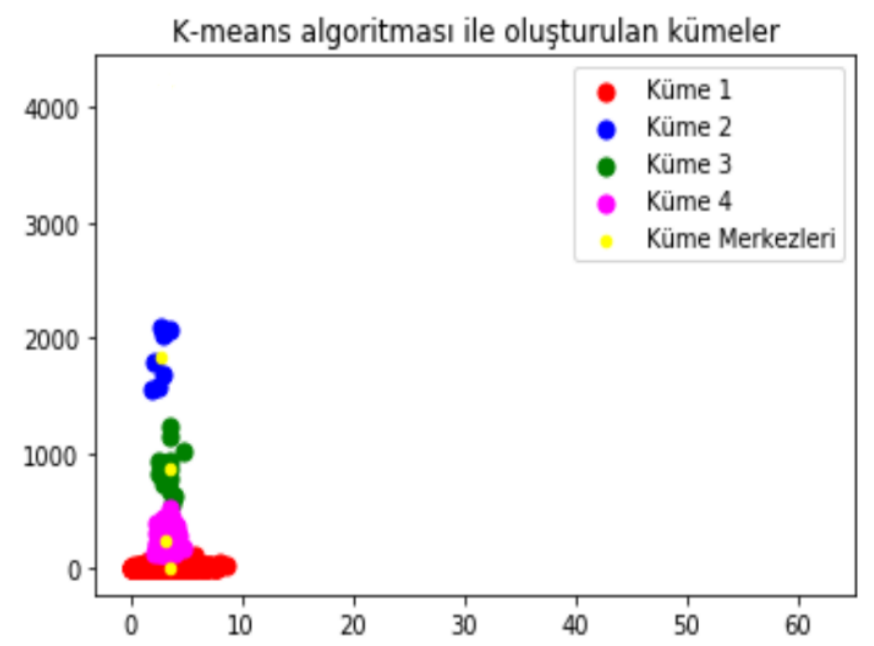

Şekil 8. Veri setinin k=4 iken k-means algoritması ile kümelenmiş grafiği

Çalışmada en fazla veri toplama sürecinde problem yaşandı. Bundan sonraki çalışmalarda hasta başı monitörleri kullanılarak anlık veri alımı ile bu süreç kolaylaştırılabilir.

\section{Teşekkür}

$\mathrm{Bu}$ çalışma Fırat Üniversitesi Bilimsel Araştırma Projeleri Koordinasyon Birimi tarafindan MF.20.20 numaralı proje kapsamında desteklenmiştir.

\section{Kaynaklar}

[1] Sülekli H.E. (2019), Investigation of Factors Affecting Mortality and Length of Stay in Intensive Care Units with Data Mining Methods ANKARA: Hacettepe University.

[2] Can M.B, Çamur E, Koru M, Özkan Ö, Rzeyeva Z. (2009) Knowledge Discovery from Datasets: Data Mining, Baskent University.

[3] Knaus WA, Draper EA, Wagner DP, Wagner DP. (1985) APACHE II: A severity of disease classification system. Crit Care Med; 13(10):818-829. 
[4] Knaus WA, Wagner DP, Draper EA, Zimmerman JE, Bergner M et al.(1991) The APACHE III prognostic system risk prediction of hospital mortality for critical III hospitalized adults. Chest;100(6):1619- 1636.

[5] Le Gall JR, Loirat P, Alperovitch A et al.(1984) A simplified acute physiology score for ICU patients. Crit Care Med;12(11): 975-977.

[6] Marshall JC, Cook DJ, Christou NV, Bernard GR, Sprung CL, Sibbald WJ.(1995) Multiple organ dysfunction score: a reliable descriptor of a complex clinical outcome. Crit Care Med. ;23(10):1638-52.

[7] Karabiyık L.(2010) Scoring Systems in Intensive Care, Journal of Intensive Care;9(3):129143.

[8] Ramon, J. \& Fierens, D. \& Guiza, F. \& Meyfroidt, G. \& Blockeel, H. \& Bruynooghe, M. \& Berghe, G. (2007). Mining data from intensive care patines. Advanced Engineering Informatics. 21. 243-256. 10.1016/j.aei.

[9] Teker, C, Çavmak, D, Yıldırım, B , Avcı, H .(2019) UNIT COSTING IN HEALTHCARE: CASE OF A PRIVATE HOSPITAL INTENSIVE CARE UNIT. Hacettepe Journal of Health Administration 22: 97-112.

[10] Craven DE, Kunches LM, Lichtenberg DA et al.(1998) Nosocomial infection and fatality in medical and surgical intensive care unit patients. Arch Intern Med;148:1161-8.

[11] Akkoç İ. (2017) Effect of Baseline Datas on the Survival of Intensive Care Unit Patients, Med Bull Haseki ;55:106-10.

[12] Coskun E, Kaya M, Özer A.B, Karabulut E,(2020) Grouping of Intensive Care Patients with Artificial Intelligence, International Congress of Artificial Intelligence in Health.

[13] Boyrazlı, H.K., Çınar, A. (2021) "Anomaly Detection in Crowded Scenes with Machine Learning Algorithms”, DUJE, vol. 12, no.2, pp. 229- 235.

[14] Alpay Ö. (2017) Investigation of the Effect of Economic News on Bist 100 Index by Data Mining, Frrat University, Institute of Social Sciences.

[15] Das, S.; Dey, A.; Pal, A.; Roy, N. (2015). Applications of artificial intelligence in machine learning: review and prospect, International Journal of Computer Applications, C. 115, Say1. 9, 31-41.

[16] Sarıman, G .(2014) " A Study of Clustering Techniques in Data Mining: Comparison of The KMeans and K-Medoids Clustering Algorithms ". Süleyman Demirel Üniversitesi Fen Bilimleri Enstitüsü Dergisi C:15: S:192-202.

[17] Amasyal1, F. M., Ersoy, O. (2008). The performance factors of clustering ensembles, IEEE 16th Signal Processing and Communication Applications Conference, SIU.

[18] Taşçı A.E., Onan, A. (2016). "K En Yakın Komşu Algoritması Parametrelerinin Sınıflandırma Performansı Üzerine Etkisinin İncelenmesi," Akademik Bilişim , Aydın, Turkey, pp.1-8.

[19] Gündoğan E, Kaya M,(2020) Research paper classification based on Word2vec and community discovery, International Conference on Decision Aid Sciences and Application (DASA).

[20] E. Çakmak, B. Kaya and M. Kaya,(2019) "Point-of-Interest Recommendation in LocationBased Social Networks," 2019 1st International Informatics and Software Engineering Conference (UBMYK),pp. 1-5 